Doi: HTTPS://DOI.ORG/10.23910/IJBSM/2017.8.3.1610a

\title{
Study on Variability in Field Experiments of Bhal and Coastal Zone Crops and Development Yardstick
}

\author{
G. N. Motaka*, V. B. Darji, D. J. Parmar, A. D. Kalola and P. R. Vaishnav
}

Dept. of Agricultural Statistics, Anand Agricultural University, Anand, Gujarat (388 110), India

\section{Corresponding Author}

G. N. Motaka

e-mail: motkagn@yahoo.in

\author{
Article History \\ Manuscript No. AR1610a \\ Received in $9^{\text {th }}$ June, 2016 \\ Received in revised form $27^{\text {th }}$ April, 2017 \\ Accepted in final form $6^{\text {th }}$ June, 2017
}

\begin{abstract}
The data on CV \% for Bhal and coastal zone of Gujarat crops yield along with other details of 1117 field experiments conducted during 1989-90 to 2014-15 at Agriculture research station, Anand Agricultural University, Arnej and Dhandhuka center were collected and analyzed using BASIC proramme. Most of the experiments carried out in plant breeding discipline (837) among the $21 \%$ experiments had greater than $18 \%$ CV followed by Agronomy (170) among $24 \%$ experiments had greater than $18 \%$ CV. More than $88 \%$ experiments carried out in RBD and about $23 \%$ experiments of them have CV \% higher than the fiducial limit. According to different treatment, Treatments group 6-10, 16-20, 21-25 and 26-30 showed lower CV \% compared to overall average CV \%. Plot size and shape also play an important role in the precision of the experiment results. Therefore, plot size of the experiments 3 to $9 \mathrm{~m}^{2}$ seems to be optimum plot size of bhal and coastal zone crops. All the experiments conducted in these regions had 2 to 6 replications. Out of them, most of experiments were conducted with 2 to 4 replications and Most of the experiments were conducted with 2, 3 and 4 replications. The experiments with 5 replications had high variability. The upper fiducial limits (the yardstick) of CV \% at $95 \%$ confidence based on non-central ' $t$ ' distribution were worked out for accepting the results of Bhal and coastal zone crops experiments which emerged as $18 \%$.
\end{abstract}

Keywords: Experimental variability, crops, yardstick, CV \%, fiducial limit

\section{Introduction}

Statistics are used to interpret data and sometimes to determine whether data are suspect. Most researchers are familiar with the use of the least significant difference (LSD) needed to separate two or more means. Another statistical measurement familiar to many scientists and taught in most basic statistics course is the coefficient of variation or the CV. This familiar measurement was created in the late 1800 s as a measure of population variability. However, ever since it was tacitly promoted as a measure of experimental validity by (Snedecor and Cochran, 1967) its original purpose has been largely ignored. The experimental data provide information on controlled (treatment effect) and uncontrolled variation. The uncontrolled variation is expressed as experimental error, which could be quantified as an estimate called 'coefficient of variation (CV)'. Besides, fertility variation among experimental units (plots), the factors contributing toward uncontrolled variation are climatic and experimental. Therefore $\mathrm{CV}$ of field experiments varies with the situation. Lower magnitude of CV is the reflection of reliability (precision) of the experimental results. The acceptable range of $\mathrm{CV}$ advocated by various workers is based on the experience with very limited number of experiments. There is a need to develop a yardstick (critical value) for $\mathrm{CV}$ based on theory and also on a large number of experiments conducted under different situations. The present paper deals with this aspect. (Johnson and Welch, 1939) reported that for a normal distribution, the ratio of mean to standard deviation should be of the order of 3 or more. Further, they mentioned that 33\% has often been stated as the permissible upper fiducial limit of CV. (Tyagi et al., 1973; Patel et al., 1978) pointed out that CV obtained for the crops under study was found to be considerably higher than those reported from the uniformity trials. They stated that the yardstick for accepting experimental results should be worked out using CV observed in the experiments rather than in the uniformity trials. (Bajpai and Nigam, 1980) suggested a working rule for deciding the value of W2 (weight corresponds to precision of the experiment) and developed an index to evaluate agricultural field experiments statistically. (Gomez and Gomez, 1984) reported that CV varies greatly with the type of experiment, the crop grown and the character measured. They opined that the acceptable range of CV is 6 to $8 \%$ for varietal trials, 10 to $12 \%$ for fertilizer trials and 13 
to $15 \%$ for insecticidal and herbicidal trials on rice. No other information (except reviewed and reported here), is available in the literature on the yardstick of CV for field experiments on crops. (Patel et al., 2000), reported that the when the coefficient of variation in pulse experiments in RCBD exceeds $23 \%$, the experimental findings should not be considered for any purpose. (Snedecor and Cochran, 1967). They stated, knowledge of relative variation is valuable in evaluating experiments. They go on to say the coefficient of variation of the yield of hay is comparable to that of the yield of corn. Consequently, the $\mathrm{CV}$ has been used as a measure of validity for many types of agricultural experiments, from fertilizer experiments to crop performance trials. The CV was created as a measure of relative variability by (Kendall and Stuart, 1977). (Aflakpui, 1995) states that there is no such thing as a $\mathrm{CV}$ for an experiment, only for individual variates. However, a $\mathrm{CV}$ of 10 to $15 \%$ for yield in experiments is generally expected by most field crop researchers. This expectation probably originated from (Cochran and Cox's, 1957) statement that the coefficient of variation is often between $5 \%$ and $15 \%$. The basis for the $\mathrm{CV}$ is the assumption that the variance increases as the size of the mean increases. (Allen et al., 1978) reported a positive relationship for several crops, and (Gotoh and Osanai, 1959) reported a positive relationship for wheat. (Masood and Javed, 2003) reported based on the coefficients of variation the optimum plot sizes for maize trials were estimated to be $\left(14.06 \mathrm{~m}^{2}\right)$ with square shape. (Khan and Mead, 1998) presented uniformity data from field trials for improving precision of agriculture field experiments in Pakistan. (Darjiet al., 2010), developed the yardstick of CV $\%$ for forage crop experiment at $95 \%$ confidence based on non-central ' $\mathrm{t}$ ' distribution were worked out for accepting the results of forage crop experiments which emerged as $14 \%$.

\section{Materials and Methods}

The secondary data on bhal and coastal zone crops yield of 1117 field experiments conducted at Agriculture research station, Anand Agricultural University, Arnej and Dhandhuka center during 1989-90 to 2014-15 in plant breeding, agronomy, entomology and soil science disciplines on different bhal and coastal zone crops viz. Dill seed (14), Paddy (2), Sun flower (4), Castor (7), Cotton (224), Cumin (12), Gram (188), Mustard (36), Pigeonpea (9), Safflower (116), Sesame (37), Sorghum (87), Spices (2), Vegetable (5) and Wheat (374) crops were utilized for the variability study. Information on plot size, number of treatments, replications, experimental design and disciplines was collected for each experiment. The plot-wise yield data were subjected to statistical analysis and $\mathrm{CV}$ was estimated for individual experiments. The same was assumed as random variable in further analysis. $C V$ is a function of square root of mean square $(S)$ and mean $(\bar{X})$. $\mathrm{CV}=\frac{\mathrm{S}}{\bar{X}}$. ...1

The distributions of $\bar{X}$ and $S$ have simple forms and Student's $t$ distribution provides complete solution for testing the hypothesis or estimating fiducial limits relating to either $m$ or $s$, singly. But $t$ distribution cannot be used for $\mathrm{CV}=\frac{\mathrm{S}}{\bar{X}}$. (Mckay, 1932) used non-central $t$-distribution for providing fiducial limits of CV.

Let $z$ be a quantity distributed normally about zero mean with unit standard deviation and let $w$ be a quantity distributed independently as $\chi^{2}$, with degrees of freedom of $\chi^{2}$. Then, if $t$ is defined by the equation:

$\mathrm{t}=\frac{\mathrm{Z}+\delta}{\mathrm{V}}$

$\mathrm{VW}$

Where $d$ is some constant, then $t$ is distributed in a manner depending only on $d$ and $f$. This distribution is a non central $t$ distribution. When dequals zero, the distribution is the familiar Student's $t$.

Let an estimate of $V$ be $v=S /$ the sample coefficient of variation.

Now, one may write

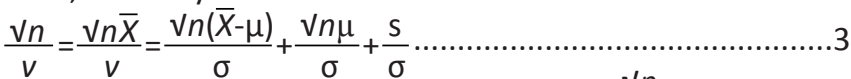

It appears from comparison with eq. (2) that $\frac{V n}{V}$ is distributed as non-central $t$ with $f=(n-1)$ and $\frac{\sigma V n}{V}$. This distribution can be used for test of significance and for providing fiducial limits of $V$ (i.e. CV), as is done for $\mu$. Since the objective was to work out the yardstick based on CV, the upper fiducial limit of CV using non-central $t$-distribution was estimated following the procedure given by (Johnson and Welch, 1939).

The procedure is briefly explained below. Let,

(i) CV $\frac{\text { Error mean square }}{\text { General mean }}$

$n=$ number of treatments $\times$ number of replications in a given experiment, $f=n-1$ degrees of freedom.

Now, the upper fiducial limit of $C V$ is,

$\mathrm{CV}_{\mathrm{uL}}=\frac{V n}{\delta}\left(\mathrm{f}, \mathrm{t}_{\mathrm{o}}, \varepsilon\right)$

Where, $\mathrm{t}_{\mathrm{o}} \mathrm{V} n=\frac{V n}{C V}$

ii) Find $Y=\left[1+\frac{t_{0}^{2}}{2 f}\right]^{-1 / 2}$ or $Y=\frac{t_{0}^{2}}{\sqrt{2 f}} 1+\frac{t_{0}^{2-1 / 2}}{2 f}$ According to whether $\frac{12}{\sqrt{2}} \frac{t_{0}^{2}}{\sqrt{2 f}}$ is greater than or less than 0.75 . Consider $Y^{\prime}$, if $\frac{t_{0}^{2}}{\sqrt{2 f}}$ lies between -0.75 and 0.75 , otherwise consider $Y$.

(iii) If $f>9$, calculate

(iv)Select desired probability level of confidence, i.e. $e$ and obtain $\lambda\left(f, t_{0}, \varepsilon\right)$ from the table in (Johnson and Welch, 1939) interpolating with respect to the quantities obtained in (ii) and (iii). (v) Calculate

$\delta\left(f, t_{0}, \varepsilon\right)=t_{0}-\lambda\left[1+\frac{t_{0}^{2}}{2 f}\right]^{-1 / 2}$

in the present investigation, the yardstick of CV for field experiments was worked out using two concepts: (i) average upper fiducial limit of $\mathrm{CV}$ for each of the 1117 bhal and coastal zone crops field experiments was worked out separately and then average of these upper fiducial limits was computed, 
and (ii) upper fiducial limit of CV based on average size of experiments, i. e. degree of freedom. The upper fiducial limit of $95 \%$ and $90 \%$ worked out using the theory of truncated $t$ distribution as described by (Johnson and Welch, 1939).

\section{Results and Discussion}

The results presented in Table 2 revealed that mean CV \% (14.31\%) and upper fiducial limit (17.83\%) of average value

\begin{tabular}{llccc}
\hline Crop/Location & Scientific name & Arnej & Dhandhuka & Average \\
\hline Dill seed & (Anethum graveolens L.) & $12.30(12)$ & $13.09(2)$ & $12.41(14)$ \\
Paddy & (Oryza sativa L.) & $8.90(2)$ & - & $8.90(2)$ \\
Sun flower & (Helianthus annuus L.) & $30.90(1)$ & $12.04(3)$ & $16.75(4)$ \\
Castor & (Ricinus communis L.) & $12.59(7)$ & - & $12.59(7)$ \\
Cotton & (Gossypium herbaceum L.) & $15.17(59)$ & $16.53(165)$ & $16.17(224)$ \\
Cumin & (Cuminum cyminum L.) & $13.16(12)$ & - & $13.16(12)$ \\
Gram & (Cicer arietinum L.) & $14.52(131)$ & $14.31(57)$ & $14.46(188)$ \\
Mustard & (Brassica juncea L.) & $16.14(17)$ & $17.10(19)$ & $16.65(36)$ \\
Pigeon pea & (Cajanus cajan L.) & $18.52(9)$ & - & $18.52(9)$ \\
Safflower & (Carthamus tinctorius L.) & $19.71(61)$ & $17.82(55)$ & $18.81(116)$ \\
Sesame & (Sesamum indicum L.) & $15.43(8)$ & $12.86(29)$ & $13.42(37)$ \\
Sorghum & (Sorghum bicolor L.) & $14.52(48)$ & $10.85(39)$ & $12.88(87)$ \\
Spices & - & $13.11(2)$ & - & $13.11(2)$ \\
Vegetable & - & $32.16(5)$ & - & $31.16(5)$ \\
Wheat & (Tritcum durum L.) & $14.11(137$ & $10.34(237)$ & $11.72(374)$ \\
Average & & $15.32(511)$ & $13.46(606)$ & $14.31(1117)$ \\
\hline
\end{tabular}

Table 2: Upper fiducial limit of CV \% for different disciplines of Bhal and Coastal zone crops

\begin{tabular}{|c|c|c|c|c|c|c|c|c|}
\hline \multirow[t]{2}{*}{ Discipline } & \multirow[t]{2}{*}{ No. of expt. } & \multirow[t]{2}{*}{ CV \% } & \multicolumn{2}{|c|}{ UL } & \multicolumn{2}{|c|}{ Range } & \multicolumn{2}{|c|}{ CV $\%>17.83$} \\
\hline & & & $(0.05)$ & $(0.10)$ & $(0.05)$ & $(0.10)$ & No. of expt. & Propo-rtion \\
\hline Agronomy & 170 & 15.14 & 18.94 & 17.98 & 3.81 & 2.85 & 42 & 0.24 \\
\hline Entomology & 70 & 16.78 & 23.86 & 21.86 & 7.09 & 5.08 & 19 & 0.27 \\
\hline Pl.Breeding & 837 & 13.93 & 17.12 & 16.34 & 3.19 & 2.40 & 184 & 0.21 \\
\hline Soil Science & 40 & 14.50 & 17.44 & 16.72 & 2.94 & 2.22 & 10 & 0.25 \\
\hline Average & 1117 & 14.31 & 17.83 & 16.95 & & & & \\
\hline
\end{tabular}

of all the discipline except for agronomy and entomology disciplines, were below the mean $\mathrm{CV} \%$. The experiments on agronomy and entomology showed large variation (average $\mathrm{CV}=15.14 \%$ and $16.78 \%$ respectively) showed poor precision may be because of experimental requirements such as sample size, natural population of pests and diseases. Use of proper statistical tools may help to improve the precision of the results. More than $24 \%$ to $27 \%$ experiments of this disciplines had more than $17.83 \%$.

The results presented in Table 3 indicated that most of the experiments were carried out in RBD and about $23 \%$ of them had CV \% higher than the fiducial limit worked out. The proportion showed 0.15 to 0.27 in split plot and FRBD.

Influence of number of treatments was also examined and results are given in (Table 4). According to different treatments group. $<6,11-15$ and $>30$ treatments in an experiment showed higher CV \% than the overall average (14.31\%).

Generally increased number of treatments in the experiments increases blocks (replication) size which increases error variance, affecting the precision of the results. Therefore, it is advisable to use such experimental designs (when treatment exceeds 30 ) which can help in controlling within block variation. Other means such as optimum plot size, more number of replications, proper site of the experiment etc. need to be considered. About 28 to $39 \%$ experiments showed higher CV \% compared to the overall average CV \% except the treatment group 6-20, 16-20, 21-25 and 25-30.

The results presented in (Table 5 ) indicated that the average CV \% for different plot size experiments were below the average CV \% (14.31) in plot size <3, 3-6, 6-9, 12-15 and $>31$ 


\begin{tabular}{|c|c|c|c|c|c|c|c|c|}
\hline \multirow[t]{2}{*}{ Design } & \multirow[t]{2}{*}{ No. of expt. } & \multirow[t]{2}{*}{ CV \% } & \multicolumn{2}{|c|}{ UL } & \multicolumn{2}{|c|}{ Range } & \multicolumn{2}{|c|}{$\mathrm{CV} \%>17.83$} \\
\hline & & & $(0.05)$ & $(0.10)$ & $(0.05)$ & $(0.10)$ & No. of expt. & Propo-rtion \\
\hline CRD & 10 & 10.00 & 12.91 & 12.18 & 2.92 & 2.18 & 0 & 00 \\
\hline FRBD & 47 & 15.96 & 19.42 & 18.59 & 3.46 & 2.62 & 13 & 0.27 \\
\hline RBD & 989 & 14.36 & 18.00 & 17.08 & 3.64 & 2.72 & 231 & 0.23 \\
\hline Split plot & 71 & 13.24 & 15.12 & 14.68 & 1.88 & 1.44 & 11 & 0.15 \\
\hline Average & 1117 & 14.31 & 17.83 & 16.95 & & & & \\
\hline
\end{tabular}

\begin{tabular}{|c|c|c|c|c|c|c|c|c|}
\hline \multirow[t]{2}{*}{ Treatments } & \multirow[t]{2}{*}{ No. of expt. } & \multirow[t]{2}{*}{ CV \% } & \multicolumn{2}{|c|}{ UL } & \multicolumn{2}{|c|}{ Range } & \multicolumn{2}{|c|}{ CV \% >17.83 } \\
\hline & & & $(0.05)$ & $(0.10)$ & $(0.05)$ & $(0.10)$ & No. of expt. & Propo-rtion \\
\hline$<6$ & 51 & 20.28 & 30.20 & 27.34 & 9.93 & 7.07 & 20 & 0.39 \\
\hline $6-10$ & 299 & 13.31 & 17.37 & 16.33 & 4.06 & 3.02 & 58 & 0.19 \\
\hline $11-15$ & 314 & 14.92 & 18.27 & 17.45 & 3.35 & 2.53 & 88 & 0.28 \\
\hline $16-20$ & 199 & 13.86 & 16.60 & 15.95 & 2.74 & 2.08 & 48 & 0.24 \\
\hline $21-25$ & 112 & 13.26 & 15.69 & 15.11 & 2.43 & 1.86 & 19 & 0.16 \\
\hline $26-30$ & 124 & 14.12 & 16.49 & 15.93 & 2.37 & 1.82 & 16 & 0.12 \\
\hline$>30$ & 18 & 16.46 & 18.89 & 18.33 & 2.43 & 1.87 & 6 & 0.33 \\
\hline Average & 1117 & 14.31 & 17.83 & 16.95 & & & & \\
\hline
\end{tabular}

Table 5: Upper fiducial limit of CV \% for different plot size of Bhal and Coastal zone crops

\begin{tabular}{|c|c|c|c|c|c|c|c|c|}
\hline \multirow[t]{2}{*}{ Plot size $\left(\mathrm{m}^{2}\right)$} & \multirow[t]{2}{*}{ No. of expt. } & \multirow[t]{2}{*}{ CV \% } & \multicolumn{2}{|c|}{ UL } & \multicolumn{2}{|c|}{ Range } & \multicolumn{2}{|c|}{ CV \% >17.83 } \\
\hline & & & $(0.05)$ & $(0.10)$ & $(0.05)$ & $(0.10)$ & No. of expt. & Propo-rtion \\
\hline$<3$ & 4 & 13.26 & 15.75 & 15.15 & 2.49 & 1.89 & 1 & 0.25 \\
\hline $3-6$ & 89 & 13.96 & 17.20 & 16.40 & 3.24 & 2.44 & 18 & 0.20 \\
\hline $6-9$ & 397 & 13.58 & 16.42 & 15.74 & 2.85 & 2.16 & 82 & 0.20 \\
\hline $9-12$ & 223 & 14.74 & 18.59 & 17.62 & 3.85 & 2.88 & 52 & 0.23 \\
\hline $12-15$ & 136 & 13.96 & 17.22 & 16.42 & 3.26 & 2.46 & 29 & 0.21 \\
\hline $15-18$ & 120 & 15.11 & 19.87 & 18.58 & 4.76 & 3.47 & 30 & 0.25 \\
\hline $18-21$ & 127 & 15.81 & 20.03 & 18.96 & 4.22 & 3.15 & 40 & 0.31 \\
\hline $24-31$ & 14 & 16.30 & 21.10 & 19.89 & 4.80 & 3.59 & 3 & 0.21 \\
\hline$>31$ & 7 & 9.84 & 13.04 & 12.21 & 3.20 & 2.37 & 0 & 00 \\
\hline Average & 1117 & 14.31 & 17.83 & 16.95 & & & & \\
\hline
\end{tabular}

sq.mt. The average $\mathrm{CV} \%$ for different plot size experiments were higher the average CV \% (14.31) in plot size 9-12, 15-18, $18-21$ and $24-31 \mathrm{~m}^{2}$. The proportion of CV \% having higher $\mathrm{CV} \%$ increased from 0.23 to 0.31 therefore, plot size of 3 to $9 \mathrm{~m}^{2}$ seems to be an optimum plot size for Bhal and coastal zone crops. Therefore, this needs to be confirmed by plot technique study for different locations.

As far as replications are concerned the most of the experiments conducted with 2, 3 and 4 replications. Among the experiments conducted with 3,4 and 5 replications showed large variation 23,24 and $41 \%$ experiments showed CV $>14.31 \%$ respectively (Table 6 ).

The CV \% data of 1117 field experiments were used to fit non central ' $\mathrm{t}$ ' distribution and to work out upper confidence limit of $\mathrm{CV}$ at 0.05 level of probability. According the upper fiducial limit of CV \% at $95 \%$ confidence level of CV \% was worked out to be $17.83 \%$. Thus the results suggested that about 18 percent $\mathrm{CV} \%$ should be considered as a yard stick for Bhal and coastal zone crop field experiments. These having CV \% >18 should be rejected for drawing scientific conclusion (Table 7). 


\begin{tabular}{|c|c|c|c|c|c|c|c|c|}
\hline \multirow[t]{2}{*}{ Replication } & \multirow[t]{2}{*}{ No. of expt. } & \multirow[t]{2}{*}{ CV \% } & \multicolumn{2}{|c|}{ UL } & \multicolumn{2}{|c|}{ Range } & \multicolumn{2}{|c|}{ CV $\%>17.83$} \\
\hline & & & (0.05) & $(0.10)$ & $(0.05)$ & $(0.10)$ & No. of expt. & Proportion \\
\hline 2 & 204 & 12.36 & 15.43 & 14.67 & 3.07 & 2.30 & 32 & 0.15 \\
\hline 3 & 385 & 14.70 & 18.18 & 17.32 & 2.48 & 2.63 & 92 & 0.23 \\
\hline 4 & 499 & 14.52 & 17.83 & 17.01 & 3.32 & 2.50 & 124 & 0.24 \\
\hline 5 & 12 & 31.97 & 52.16 & 45.96 & 20.20 & 13.99 & 5 & 0.41 \\
\hline 6 & 24 & 11.80 & 15.35 & 14.45 & 3.55 & 2.64 & 9 & 0.37 \\
\hline Mean & 1117 & 14.31 & 17.83 & 16.95 & & & & \\
\hline
\end{tabular}

Table 7: The average upper fiducial limit and yardstick for CV \% for the experiments of Bhal and Coastal zone crops

\begin{tabular}{|c|c|c|c|c|c|}
\hline \multirow[t]{2}{*}{$\begin{array}{l}\text { Name of } \\
\text { crop }\end{array}$} & \multirow{2}{*}{$\begin{array}{l}\text { No. } \\
\text { of } \\
\text { expt. }\end{array}$} & \multirow[t]{2}{*}{$\begin{array}{l}\text { Mean } \\
\text { CV \% }\end{array}$} & \multicolumn{2}{|c|}{$\begin{array}{l}\text { Upper fiducial } \\
\text { limit of CV \% }\end{array}$} & \multirow{2}{*}{$\begin{array}{c}\text { Overall } \\
\text { yardstick } \\
\text { of CV\% }\end{array}$} \\
\hline & & & 0.95 & 0.90 & \\
\hline $\begin{array}{l}\text { Bhal and } \\
\text { coastal } \\
\text { zone crops }\end{array}$ & 1117 & 14.31 & 17.83 & 16.95 & $18 \%$ \\
\hline
\end{tabular}

The power of $\mathrm{F}$ test was examined with the non significant/ significant ratio of experiments (Table 8). The results revealed that the ratio consistently increased with the increase in $\mathrm{CV}$ of the experiments. It also indicated that the efficiency (of detecting difference in treatment means) of F-test decreased with the increase in $\mathrm{CV}$ of experiments. The average ratio was

\begin{tabular}{lcccc}
\hline \multicolumn{5}{l}{ Table 8: Power of F-test as influence by CV \% } \\
\hline Classes & No. of & \multicolumn{4}{c}{ F-test } \\
\cline { 3 - 5 } CV \% & Exp. & Significant & Non-significant & Ratio \\
\hline $1.0-10.0$ & 408 & 369 & 39 & 0.11 \\
$11.0-21.0$ & 545 & 400 & 145 & 0.36 \\
$21.0-31.0$ & 122 & 56 & 66 & 1.18 \\
$31.0-41.0$ & 35 & 12 & 23 & 1.92 \\
$41.0-51.0$ & 3 & 0 & 3 & 0.00 \\
$51.0-61.0$ & 2 & 1 & 1 & 1.00 \\
$61.0-71.0$ & 0 & 0 & 0 & 0.00 \\
$71.0-81.0$ & 0 & 0 & 0 & 0.00 \\
$81.0-91.0$ & 0 & 0 & 0 & 0.00 \\
$91.0-100$ & 2 & 0 & 2 & 0.00 \\
Total & 1117 & 838 & 279 & 0.33 \\
\hline
\end{tabular}

observed to be 0.33 . The ratio for the class $11.0-21.0 \%$ was almost equal to the average ratio which included $14.3 \%$, the mean $\mathrm{CV}$ of all experiments.

\section{Conclusion}

Most of experiments of plant breeding discipline were conducted in RBD. Number of treatments $6-10,16-20$ and 21-25 showed lower CV \% as compared to overall average $\mathrm{CV} \%$. Size of plot 3 to $9 \mathrm{~m}^{2}$ seems to be optimum plot size and most of the experiments conducted with the 3, 4 and 5 replications. When the coefficient of variation in Bhal and coastal zone crops field experiments exceeds $18 \%$, the experimental finding should not be considered for any scientific purpose.

\section{Acknowledgement}

Research scientist, Agriculture research station, AAU, Arnej center and Assistant Research Scientist, Agricultural Research Station, Anand Agricultural University, Dhandhuka for providing necessary data.

\section{References}

Aflakpui, G.K.S., 1995. Some uses/abuses of statistics in crop experimentation. Tropical Science 35, 347-353.

Allen, F.L., Comstock, R.E., Rasmusson, D.C., 1978. Optimal environments for yield testing. Crop Science 18, 747-751.

Bajpai, S.N., Nigam, A.K., 1980. Statistical evaluation of Agricultural field experiments.Journal of Indian Society of Agricultural Statistics 32(2), 41-45.

Cochran, W.G., Cox, G.M., 1957. Experimental designs. John Wiley \& Sons, New York.

Darji, V.B., Bhatt, B.K., Dixit, S.K., 2010. Variability in forage crop field experiments and yardstick thereof. Agriculture Science Digest 30(4), 266-269.

Gomez, K.A., Gomez, A.A., 1984. Statistical procedure for Agricultural workers, John Wiley and Sons, New York, $2^{\text {nd }}$ ed.

Gotoh, J., Osanai, S., 1959. Efficiency of selection for yield under different fertilizer levels in a wheat cross. Japan Journal of Breeding 9, 173-178.

Johnson, N.L., Welch, B.L., 1939. Application of no central t-distribution. Biometrika 31, 362-389.

Kendall, M., Stuart, A., 1977. The advanced theory of statistics. Vol. 1. Distribution theory. $4^{\text {th }}$ ed. MacMillan, New York. 
Khan, M.I., Mead, R., 1998. Improving Precision of Agriculture Field Experiments in Pakistan. Gomal University Journal Research 18, 33-48.

Masood, M.A., Javed, M.A., 2003. Variability in field experiments in maize crop in Pakistan. Pakistan Journal of Agricultural Science 40, (3-4).

McKay, A.T., 1932. Distribution of the coefficient of variation and the extended " $\mathrm{t}$ " distribution. Journal of the Royal Statistical Society 95, 695-698.

Patel, J.K., Patel, N.M., Shiyani, R.L., 2001. Coefficient of variation in field experiments and yardstick thereof-
Anempirical study, Current Science 81(9), 1162-1164.

Patel, N.M., Prajapati, M.R., Prajapati, K.H., 1978. Paper presented at XVII Annual conference of Gujarat Statistical Association, Anand, November, 4-5.

Snedecor, G.W., Cochran, W.G., 1967. Statistical Methods. (6 $6^{\text {th }}$ Edition), Oxford and IBH Pub. Co., New Delhi.

Tyagi, B.N., Kathuria, O.P., Sahni, M.L., Kulharni, G., 1973. A study of coefficient of variation associated with plots and blocks of different sizes for some important field crops.Journal of Indian Society of Agricultural Statistics XXV (II), 37-47. 